\title{
RELATION BETWEEN EXPECTED RETURN AND VOLATILITY AT BUCHAREST STOCK EXCHANGE, ON BUSINESS CYCLE STAGES
}

\author{
Viorica Chirilă ${ }^{1}$ \\ Ciprian Chirilă ${ }^{2}$
}

ABSTRACT: The study of the relation between risk and return is an important topic for investors in financial assets, which is the reason why many researchers have tackled it. It is only natural for an investor with aversion for risk, who undertakes a higher risk investment, mare to expect be rewarded accordingly, that is to achieve higher return rates. The research conducted on various stock markets had contradictory results, which means that the existence of such a connection is not certain on all stock markets. According to a new hypothesis, tackled by the latest studies, the aversion for risk of rational investors may be related to the stages of the business cycles. This paper deals with the connection between expected return and volatility at Bucharest Stock Exchange, by analyzing the return and volatility of the BET index portfolio. In order to assess this relation, we employed heteroskedastic autoregressive models. The study was conducted between January 2000 and April 2011, as well as during two sub-periods determined by different business cycle phases: economic growth and recession. The results revealed significant differences between the whole analyzed period and the economic growth and recession sub-periods. By studying BSE return throughout the analyzed period, we conclude that there is no relationship between expected return and risk, whereas volatility is asymmetric. Actually, one may witness a relation between return and risk, as well as a non-asymmetric response of volatility to shocks during economic growth, and no risk-return relationship and asymmetric volatility during economic recession. Also, results have shown a positive relationship between return and volatility during economic growth, and a negative relationship between the same during economic recession.

Keywords: business cycle, return, volatility, return-volatility relation

JEL Classification: $611, C 58$

\section{Introduction}

In 1990 William Sharpe was awarded the Nobel Prize for the Capital Asset Pricing Model that he developed in 1964 which marked the beginning of the asset pricing theory. This prize pointed out the importance of studying the connection between risk and return, to which researchers have given special consideration since. Somewhat later, Lintner (1965) and Mossin (1966) succeeded in reaching the same model independently of the Nobel Prize winner. According to the theoretical asset pricing models, a risk-averse investor who makes riskier investments should expect to be rewarded accordingly, i.e. to achieve higher rates of return. These models promote a positive relationship between expected return and volatility. Empirical research conducted on stock markets concerning the relationship between expected return and volatility led to contradictory results. Some studies revealed a positive relation between return and volatility, whereas other studies demonstrate a negative relationship. For example Baillie and DeGennarro (1990) found only a weak and almost non-existent relationship on the US stock market. Koulakiotis, Papasyriopoulos and

\footnotetext{
${ }^{1}$ University Alexandru Ioan Cuza from Iaşi, Romania, Faculty of Economics and Business Administration, Department of Economics, Quantitative Analysis and Information Systems, e-mail: chviorica@yahoo.com

${ }^{2}$ University Alexandru Ioan Cuza from Iaşi, Romania, Faculty of Economics and Business Administration, Department of Economics, Quantitative Analysis and Information Systems,e-mail: chcipis@yahoo.com
} 
Molyneux (2006), Theodossiou and Lee (1995) discovered no significant relationship. In contrast, Glosten, Jagannathan and Runkle (1993) on the US market, and Dimitriou and Simos (2011) in almost all twelve EMU countries as well as five of the major EMU international stock markets documented a negative and significant relationship.

According to a new hypothesis, tackled by the latest studies on the relation between return and volatility, the aversion for risk of rational investors may be related to the stages of the business cycles (Kim and Lee, 2008).

The study of the return and risk related to stocks, to stock portfolios and to stock index portfolios has led to the identification of specific empirical characteristics (also known by the name of stylized facts). As for financial assets return rates, they are strongly leptokurtic (which feature is also known by the name of "fat tails"). Given the excessively curved distributions, the return rates fail to observe a normal distribution law. The feature of return distributions called "fat tails" shows that the extreme values of the variables concerned occur more frequently than in normal distribution.

This dependence reveals that high (positive or negative) return rates are followed by other extreme return rates, regardless of their sign (Berdot, 2003). The existence of this return dependence suggests that return rates may be modeled using ARCH (Autoregressive Conditional Heteroskedasticity) models.

Stock return volatility is characterized by stationarity, asymmetry and clustering.

Volatility stationarity means that volatility is not divergent at infinitum, but that it varies without fixed boundaries.

Volatility asymmetry refers to the fact that volatility is higher on an assets/stock market whose prices tend to decrease than on a stock market whose prices tend to increase. The existence of such a characteristic plays an important role in risk management, in hedging strategies and also when setting the option prices. Some of the identified factors, which are crucial for this feature, are the market leverage effect, volatility feedback and psychological investment factors, which are determined by the perception of the risk/profit balance at various market levels.

Volatility clustering is a return volatility characteristic according to which big variations are followed by big variations and small variations are followed by small variations (Mandelbrot, 1963). This characteristic shows that a chock (which takes the form of new information) occurring on a stock market is long lasting.

The purpose of our paper is:

- to determine the characteristics of the return rates and volatility of Bucharest Stock Exchange during the above-mentioned period, as well as during the economic growth and recession periods;

- to study the relation between the expected return and volatility during the above-mentioned period, as well as during the economic growth and recession periods, considering the previously determined empirical characteristics of return and volatility.

In order to achieve these goals, the second part of the paper is devoted to a short description of the methods employed to determine the business cycle stages and to examine the relation between return and volatility. In the third part, we will describe the main results obtained further to the analysis of the connection between return and volatility at Bucharest Stock Exchange. The fourth part, which ends the paper, will include the conclusions of the empirical analyses performed. The results reveal that the connection between return and volatility at Bucharest Stock Exchange should be analyzed on business cycle stages. The results obtained during the economic growth periods are considerably different from those relating to economic recession periods. Therefore, investors, especially those who has aversion for risk, should develop strategies based on the stock exchange return and volatility characteristics, depending on the business cycle stages. 


\section{Methods Employed}

In order to analyze the return and risk characteristics at Bucharest Stock Exchange, on business cycle stages, we will begin by determining the business cycle stages and then by examining the return and risk characteristics, depending on the business cycle stages we identified. Therefore, we will describe hereunder the methods that we will employ.

Real gross domestic product and especially industrial production index are often used to estimate business cycles. However, since the Romanian gross domestic product is available only on quarterly basis, we will use the industrial production index, which is available on monthly basis.

The identification of the exact times of business cycle phase changing is known as cycle dating. One of the most frequent and simple methods of cycle dating was proposed by Bry and Boschan (1971). Bry's and Boschan's dating algorithm (1971) enables one to identify the local trough or peak in a $\mathrm{Y}_{\mathrm{t}}$ time series transformed by logarithm processing. A possible peak is identified when a value $y$ of the time series is higher than $k$ values of the $Y_{t}$ variable in both directions [t-k, $\mathrm{t}+\mathrm{k}]$, whereas a possible trough is identified when a value $\mathrm{y}$ of the time series is lower than $\mathrm{k}$ values of the Yt variable in both directions [t-k, $\mathrm{t}+\mathrm{k}]$.

The possible peak or trough changing times that were identified should take into account the following items of what is commonly called censuring rules, in order to be validated:

- the business cycle changing times should alternate, meaning that a peak should be followed by a trough, then by another peak and so on. For example, whenever two successive peaks are identified, one of them should be removed, namely the one with the lowest industrial production index;

- as concerns parameter $\mathrm{k}$, Bry and Boschan (Bry and Boschan, 1971) suggest $\mathrm{k}=5$ for monthly data;

- the minimum duration of a complete cycle (i.e. from peak to peak and/or trough to trough) should be fifteen months;

- according to Harding and Pagan (Harding and Pagan, 2001), the minimum duration of a business cycle stage should be six months;

- the changing times (peak and/or trough) determined at the beginning and at the end of the industrial production index series should be removed, as they are obtained by comparing them with the first and last series value, respectively.

In our opinion, after having identified and validated the business cycle changing times, economic growth occurs during the periods between a trough and a peak, whereas recession onsets during the periods between a peak and trough.

Since assets return rates are dependent, they may be modeled using auto regressive conditional models (Mills, 1999; Nelson, 1991; Boolerslev, 1986;). Each of the autoregressive conditional models tried to take into consideration as many empirical return and volatility characteristics as possible.

Autoregressive conditional models include two equations: conditional moving-average equation and conditional volatility equation.

The conditional moving-average equation is generally a ARMA model. Nevertheless, this equation may also include other return influence factors (such as macroeconomic variables).

We will specify hereunder the conditional volatility equation of each model.

The ARCH (Autoregressive Conditional Heteroskedasticity) model was proposed by Engle in 1982. When he developed this model, Engle considered the leptokurtic nature of return rates, also called "fat tails", and return volatility variation with time (Engle at al. 1987; Engle and Bollerselv, 1986).

An $\operatorname{ARCH}(2)$ model based on an $\operatorname{ARMA}(1,1)$ model takes the form of the following equation:

- ARMA(1,1) return model: $r_{t}=a_{0}+a_{1} r_{t-1}+\varepsilon_{t}-m_{1} \varepsilon_{t-1}$ 


$$
-\sigma_{t}^{2}=\alpha_{0}+\alpha_{1} \varepsilon_{t-1}^{2}+\alpha_{2} \varepsilon_{t-2}^{2}
$$

where:

$r_{t}$ - return of the index portfolio under survey;

$\sigma_{t}^{2}$ - conditional error variance; conditional error variance is an error forecast for the $t$ day, considering the information available at the t-1 time;

The following requirements should be met in order for conditional variance to be null or positive: $\alpha_{0}>0, \alpha_{1}, \alpha_{2}, \ldots, \alpha_{p} \geq 0$.

Since the analysis revealed a very high ARCH model order, the GARCH model was considered an improvement of the former. The GARCH model manages to consider, in addition to the characteristics taken into account by the ARCH model, volatility clustering.

The GARCH (Generalized Autoregressive Conditional Heteroskedasticity) model enables one to predict conditional volatility, depending on the previous errors of the model, as well as on the previous volatility predictions. Conditional volatility in the GARCH model is an autoregressive process.

The $\operatorname{GARCH}(\mathrm{p}, \mathrm{q})$ model takes the form of the following equations:

- ARMA $(1,1)$ return model: $r_{t}=a_{0}+a_{1} r_{t-1}+\varepsilon_{t}-m_{1} \varepsilon_{t-1}$

- $\sigma_{t}^{2}=\alpha_{0}+\alpha_{1} \varepsilon_{t-1}^{2}+\alpha_{2} \varepsilon_{t-2}^{2}+\ldots+\alpha_{p} \varepsilon_{t-p}^{2}+\beta_{1} \sigma_{t-1}^{2}+\ldots+\beta_{q} \sigma_{t-q}^{2}$

The following requirements must be met in order for the $\sigma_{t}^{2}$ conditional variance to be positive:

$\alpha_{0}>0, \alpha_{i} \geq 0, \beta_{i} \geq 0$. Also, the stationarity requirement is met if $\alpha_{i}+\beta_{i}<1$.

The GARCH-M (GARCH in Mean) model allows considering the connection between risk and return. According to these models, there is a direction connection between the risk that is undertaken and the return that is expected: the higher the risk undertaken by investors, the higher their award should be. Therefore, the moving-average equation will include expected volatility, as explanatory variable, which may be measured by both standard deviation and variance.

The GARCH(p,q)-M(1) model is as follows:

- return model $r_{t}=a_{0}+a_{1} r_{t-1}+\varepsilon_{t}-m_{1} \varepsilon_{t-1}+b_{1} \sigma_{t}$

- $\sigma_{t}^{2}=\alpha_{0}+\alpha_{1} \varepsilon_{t-1}^{2}+\alpha_{2} \varepsilon_{t-2}^{2}+\ldots+\alpha_{p} \varepsilon_{t-p}^{2}+\beta_{1} \sigma_{t-1}^{2}+\ldots+\beta_{p} \sigma_{t-q}^{2}$

The following requirements must be met in order for the $\sigma_{t}^{2}$ conditional volatility to be positive: $\alpha_{0}>0, \alpha_{i} \geq 0, \beta_{i} \geq 0$ and $\alpha_{i}+\beta_{i}<1$.

EGARCH, PARCH, GJR-GARCH are models that have been developed to consider the asymmetric shock impact on return.

The EGARCH model manages to consider the asymmetric impact of new events on return: a negative piece of information having the same intensity as a positive piece of information determines a higher volatility increase.

The EGARCH $(1,1)$ model includes the following equations:

- ARMA return model: $Y_{t}=a_{0}+a_{1} r_{t-1}+\varepsilon_{t}-m_{1} \varepsilon_{t-1}$

$-\ln \sigma_{t}^{2}=\alpha_{0}+\alpha_{1}\left|\frac{\varepsilon_{t-1}}{\sqrt{\sigma_{t-1}^{2}}}\right|+\gamma_{1} \frac{\varepsilon_{t-1}}{\sqrt{\sigma_{t-1}^{2}}}+\beta_{1} \ln \sigma_{t-1}^{2}$

The asymmetry is revealed by parameter $\gamma_{1}$. If this parameter is statistically significant, there is an asymmetric volatility reaction, depending on the new information on the market.

As we also want to consider the information asymmetry effect when estimating the relation between expected return and conditional volatility, the EGACH-M model provides this option.

EGARCH-M model: 


$$
\begin{aligned}
& r_{t}=a_{0}+a_{1} r_{t-1}+\varepsilon_{t}-m_{1} \varepsilon_{t-1}+b_{1} \sigma_{t} \\
& \ln \sigma_{t}^{2}=\alpha_{0}+\alpha_{1}\left|\frac{\varepsilon_{t-1}}{\sqrt{\sigma_{t-1}^{2}}}\right|+\gamma_{1} \frac{\varepsilon_{t-1}}{\sqrt{\sigma_{t-1}^{2}}}+\beta_{1} \ln \sigma_{t-1}^{2}
\end{aligned}
$$

Since the EGARCH and EGARCH-M models have conditional volatility in logarithmic form as a dependent variable, no more requirements should be met in order to provide a positive value of this parameter.

If, when estimating this model, we get a statistically significant $b_{1}$ we may say that there is a relation between return and volatility. Also, if $\gamma_{1}$ is statistically significant, we may consider volatility as asymmetric.

Ding et al. (1993) propose the Asymmetric Power ARCH (APARCH). Conditional variance for a $\operatorname{APARCH}(1,1,1)$ is modeled by the equation:

$$
\sigma_{t}^{\delta}=\alpha_{0}+\alpha_{1}\left(\left|\varepsilon_{t-1}\right|-\gamma_{1} \varepsilon_{t-1}\right)^{\delta}+\beta_{1} \sigma_{t-1}^{\delta}
$$

The recorded parameters must meet the following requirements $\delta \geq 0, \alpha_{0}>0, \alpha_{1} \geq 0, \beta_{1} \geq 0$ and $\left|\gamma_{1}\right| \leq 1$. If $\gamma_{1} \neq 0$, conditional volatility is asymmetric.

GJR-GARCH is another asymmetric model introduced by Glosten et al. (1993). A GJR(1,1) model has the following conditional variance equation:

$$
\sigma_{t}^{2}=\alpha_{0}+\alpha_{1} \varepsilon_{t-1}^{2}+\gamma_{1} S_{t-1}^{-} \varepsilon_{t-1}^{2}+\beta_{1} \sigma_{t-1}^{2}
$$

where $S_{t-1}^{-}$is a dummy variable, which is 1 when $\varepsilon_{t-1}<0$ and 0 in all the other situations.

The model requires that $\alpha_{1}+\beta_{1}+\frac{1}{2} \gamma_{1}<1, \alpha_{0}>0, \alpha_{1} \geq 0, \beta_{1} \geq 0, \alpha_{1}+\gamma_{1} \geq 0$. When $\gamma_{1}<0$, conditional variance will be higher after a negative shock at moment $\mathrm{t}\left(\varepsilon_{t-1}<0\right)$.

In order to estimate conditional volatility, Engle (1983) used normal distribution, Bollerslev (1987) proposed standardized Student t distribution, and Nelson (1991) poposed Generalized Error Distribution (GED). Our study estimates heteroscedastic models relying on these three distributions. Once the heteroscedastic models have been estimated, we tested specific regression model estimation assumptions. Then we chose the best model depending on Adjusted $\mathrm{R}^{2}$ and the Akaike, Schwarz, Hannan-Quinn information criteria.

\section{Main Empirical Results}

The data used in this study is gathered from two sources: Eurostat database for industrial production and Datastream for index BET.

Our research first tackled business cycle dating in Romania based on the Bry and Boschan dating algorithm (Bry and Boschan, 1971) and then return-volatility relation modeling by means of the heteroskedastic EGARCH-M model.

As concerns Romanian business cycle dating, we employed the monthly industrial production index. The data were found in the Eurostat database and they refer to the January $2010-$ April 2011 period. As shown in figure 1 a), the industrial production index has a monthly seasonality, and that is the reason why we used the deseasonalized series provided by Eurostat. 

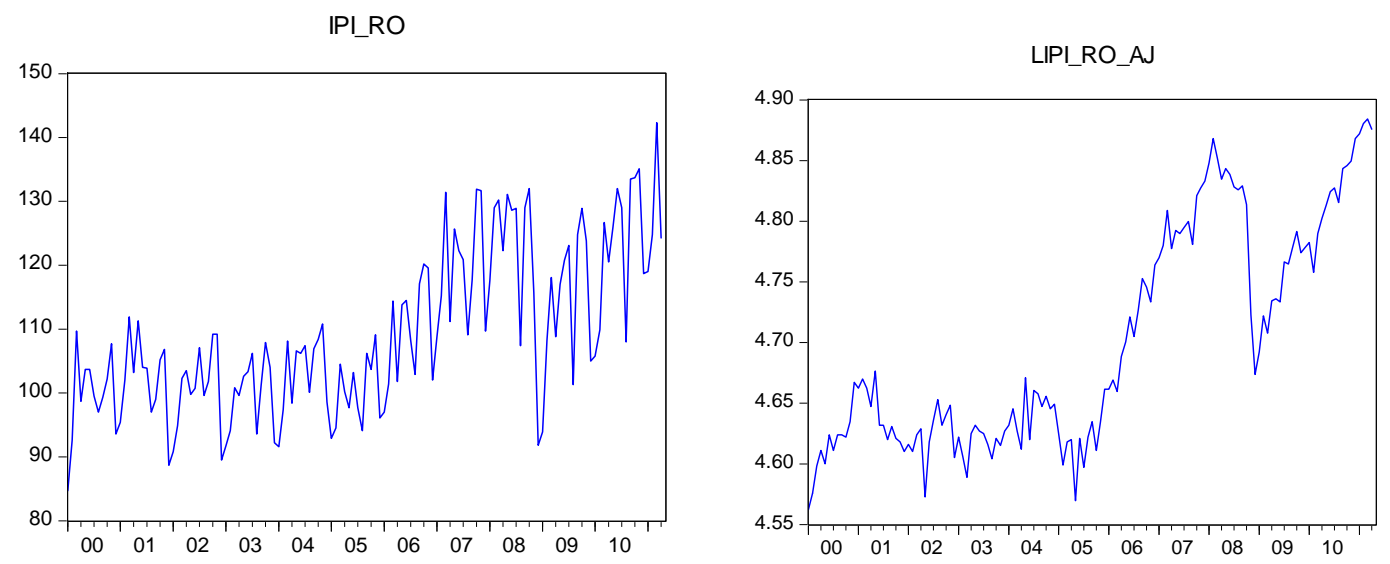

a) industrial production index

b) industrial production index adjusted on seasonal and logarithmic basis

Figure no. 1. - Evolution of the industrial production index in Romania, between January 2000 and April 2011

The methods provided by Bry and Boschan (1971) enabled us to calculate the business cycle stage changing times, which are shown in the table below:

Business cycle changing times in Romania
\begin{tabular}{|c|c|}
\hline peak & trough \\
\hline $5 / 2001$ & $5 / 2002$ \\
\hline $5 / 2003$ & $5 / 2005$ \\
\hline $3 / 2007$ & $12 / 2008$ \\
\hline
\end{tabular}

Table no. 1

According to the results obtained, we achieved, in addition to the initial time series, two time series, which include the BET index price values, marketable on Bucharest Stock Exchange, during both economic growth and recession.

We calculated the daily return rates beginning with January 1, 2000 until April 27, 2011, based on the daily prices of the BET index at Bucharest Stock Exchange. Continuously compounded return, also called logarithmic return, is calculated as follows:

$$
r_{t}=\left(\ln P_{t}-\ln P_{t-1}\right) \cdot 100
$$

where: $r_{t}$ - continuously compounded return

$P_{t}, P_{t-1}$ - index portfolio price at time $\mathrm{t}$ and $\mathrm{t}-1$, respectively

The BET index portfolio return throughout the whole analyzed period continues to be known under the name of LRBET, the BET index portfolio return during the economic growth periods is called CLRBET, whereas the same return during the economic recession periods is called SLRBET.

The first return analysis stage is the identification of its characteristics. Therefore, we analyzed the descriptive statistics of the three rates of return under survey, namely LRBET, CLRBET and SLRBET. The results are shown in the table below. 
Table no. 2

Descriptive statistics of the BET index portfolio return rates throughout the whole analyzed period, as well as during the economic growth and recession periods

\begin{tabular}{|l|l|l|l|}
\hline & LRBET & CLRBET & SLRBET \\
\hline Mean & 0.08732 & 0.10185 & 0.04383 \\
\hline Median & 0.02762 & 0.02217 & 0.05100 \\
\hline Max & 11.5444 & 10.5645 & 11.5444 \\
\hline Min & -13.1167 & -13.1168 & -11.9018 \\
\hline Std. Dev. & 1.78708 & 1.67744 & 2.081708 \\
\hline Skewness & -0.37060 & -0.39314 & -0.29922 \\
\hline Kurtosis & 10.24988 & 10.0952 & 9.50152 \\
\hline Jarque-Bera & 6539.19 & 4703.24 & 1314.36 \\
\hline Prob. & 0.00000 & 0.00000 & 0.00000 \\
\hline Sum & 258.037 & 225.600 & 32.4361 \\
\hline Sum Sq. Dev. & 9434.08 & 6229.76 & 3202.46 \\
\hline Obs. & 2955 & 2215 & 740 \\
\hline
\end{tabular}

During the analyzed period, the BET index portfolio has a low, yet positive $(0.08732 \%)$, mean return rate. If we bear in mind that these return rates are daily, they may increase considerably throughout a month. Therefore, when the return rates are stationary, investors who own a portfolio similar to the BET index portfolio expect to have profit. The BET index portfolio return rates during the economic growth periods, called CLRBET, and during the economic recession periods, called SLRBET, are also positive. However, investors expect to attain higher return rates during economic growth than during economic recession periods. The BET index portfolio risk, measured by standard deviation, is much higher during economic recession periods (2.081708) than during economic growth periods (1.67744). As the return rate medians are positive, more than $50 \%$ of the return rates are positive, which means that it is more likely for investors to have profit than to suffer losses.

The distributions of all the return rates under survey, namely LRBET, CLRBET and SLRBET, are all characterized by negative asymmetry (the asymmetry indicators are -0.37060 , 0.39314 and -0.29922 , respectively), which means that these distributions lengthen towards the low, negative values of the return rates. Also, as it is the case with most of financial series, their distributions are characterized by excess leptokurtosis (the distribution curving indicators are much higher than 3, which is specific to mesokurtic distributions: 10.24988, 10.0952 and 9.50152, respectively).This means that investors may either have very high profit, or suffer great losses.

According to the graphic representation of the BET index portfolio return rates shown below, there are periods when the return rates have low, both positive and negative, values and, also, periods when the return rates have high, both positive and negative, values. Thus, the graphic representations show index portfolio return rates show volatility clustering. 


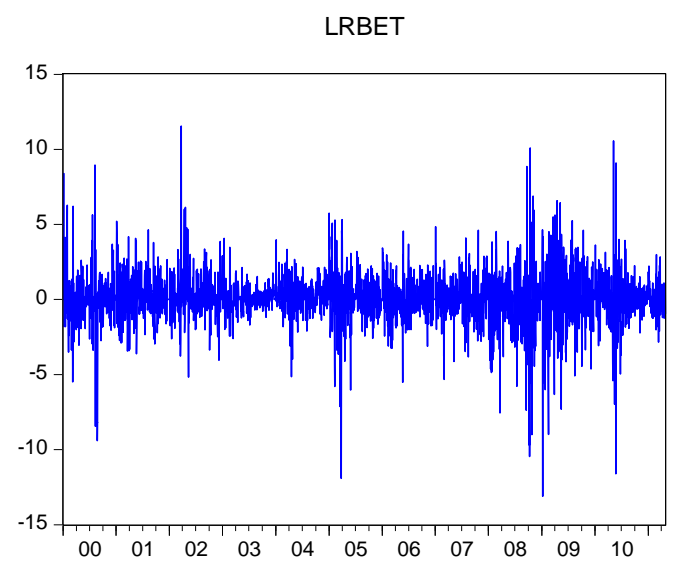

Figure no. 2. - Evolution of the BET index portfolio return rate between January 2000 and April 2011

In order to test the volatility clustering hypothesis, which would actually mean that return rates are dependent, we should begin by examining whether the squares of the return rates are autocorrelated. The Ljung-Box test enables us to do that. According to the null hypothesis of the Ljung-Box test, the squares of the return rates are not autocorrelated, whereas according to the alternative hypothesis the squares of the return rates are autocorrelated. Since the probabilities associated to the Ljung-Box $(\mathrm{Q})$ test are lower than the risk undertaken for testing these hypotheses of 0.05 , the null hypothesis is rejected, and the alternative return rate dependence hypothesis is accepted.

Table no. 3

Total and partial autocorrelation functions, the Ljung-Box test and probabilities associated to the Ljung-Box test

\begin{tabular}{|c|c|c|c|c|c|c|c|c|c|c|c|c|}
\hline & \multicolumn{4}{|c|}{ LRBET2 } & \multicolumn{4}{|c|}{ LRBET_C2 } & \multicolumn{4}{|c|}{ LRBET_FI2 } \\
\hline & AC & PAC & Q-Stat & Prob & $\mathrm{AC}$ & PAC & Q-Stat & Prob. & AC & PAC & Q-Sta & Prob. \\
\hline 1 & 0.314 & 0.314 & 291.55 & 0.000 & 0.302 & 0.302 & 269.75 & 0.000 & 0.349 & 0.349 & 333.95 & 0.000 \\
\hline 2 & 0.230 & 0.145 & 447.54 & 0.000 & 0.249 & 0.174 & 453.47 & 0.000 & 0.257 & 154 & 515. & 0.000 \\
\hline 3 & 0.158 & 0.057 & 521.15 & 0.000 & 0.183 & 0.078 & 552.92 & 0.000 & 0.198 & 0.079 & 622.33 & 000 \\
\hline 4 & 0.105 & 0.018 & 553.50 & 0.000 & 0.166 & 0.069 & 634.18 & 0.000 & 0.173 & 0.066 & 704.89 & 0.000 \\
\hline 5 & 0.103 & 0.044 & 04 & 0.000 & 0.139 & 0.044 & 691.48 & 0.000 & 0.162 & 0.061 & 777.34 & 0.000 \\
\hline 6 & 0.083 & 0.024 & 605.45 & 0.000 & 0.112 & 0.022 & 728.60 & 0.000 & 0.119 & 0.012 & 816.48 & 0.000 \\
\hline 7 & 0.102 & 0.053 & 636.33 & 0.000 & 0.147 & 0.077 & 792.96 & 0.000 & 0.132 & 0.050 & 864.10 & 0.000 \\
\hline 8 & 0.101 & 0.041 & 666.67 & 0.000 & 0.134 & 0.047 & 846.47 & 0.000 & 0.160 & 0.080 & 934.62 & 0.000 \\
\hline 9 & 0.126 & 0.066 & 713.97 & 0.000 & 0.147 & 0.059 & 910.91 & 0.000 & 0.138 & 0.032 & 987.09 & 0.000 \\
\hline 10 & 0.151 & 0.078 & 782.01 & 0.000 & 0.170 & 0.079 & 996.80 & 0.000 & 0.171 & 0.079 & 1067.8 & 0.000 \\
\hline 11 & 0.204 & 0.121 & 905.29 & 0.000 & 0.206 & 0.104 & 1123.0 & 0.000 & 0.166 & 0.053 & 1143.4 & 0.000 \\
\hline 12 & 0.187 & 0.066 & 1009.3 & 0.000 & 0.183 & 0.052 & 1221.9 & 0.000 & 0.166 & 0.047 & 1218.9 & 0.000 \\
\hline
\end{tabular}

Remark: Results obtained by means of the Eviews software

The presence of the return rate dependence suggests that the return rates may be modeled using ARCH (Auto Regressive Conditional Heteroskedasticity) models. This is possible since the analyzed return rates, namely LRBET, CLRBET and SLRBET, are autocorrelated. 
The first return modeling stage consists of testing their stationarity. As the Akaike and Schwatz criteria provide contradictory results for all the return rates with Augmented Dickey-Fuller and Philips-Perron tests we used the KPSS test for the stationarity testing (Appendix 1).

For the KPSS test, the Akaike and Schwarz criteria provide the same results. CLRBET is stationary, whereas SLRBET and LRBET are not stationary and have a descending trend. These non-stationary return rates will become stationary if the trend is excluded. The descending trend of SLRBET and LRBET shows us that the return rates diminished throughout the analyzed period, as well as during economic recession.

After the return rates have become stationary, we tested stationary return rate autocorrelation. The total and partial return rate autocorrelation functions are infinite and tend to zero, which shows us that they may undergo ARMA modeling. The orders of these models were determined by tests based on the Schwarz criterion. The results obtained confirm that the lowest Schwarz criterion value is achieved for the AR(1) model. Hence, the heteroskedastic model mean equation is a $\operatorname{AR}(1)$ model.

In order to determine the relation between return and volatility, and also in order to consider a possible volatility asymmetry, we estimated the GARCH, GARCH-M, EGARCH, EGARCH-M, A-PARCH, A-PARCH-M, GJR, GJR-M models for each of the three return series analyzed, namely LRBET, CLRBET and SLRBET, relying on the three distributions described above, i.e. normal, student and GED. Appendices 3, 4 and 5 show the information criteria for some of these models.

As concerns CLRBET, only two of the estimated models meet the specific regression model assumptions and the restrictions imposed by each model. These models are: EGARCH(1,1)$\mathrm{M}$ (Student) and APARCH(1,1)-M (normal distribution). From the information criteria standpoint, EGARCH(1,1)-M (Student distribution) is the best model. The results are shown in table 4.

According to appendix 4, for SLRBET, only the estimated GJR(1,1)-M models fail to meet the specific regression model assumptions. From the information criteria viewpoint, EGARCH$\mathrm{M}(1,1)$ (GED) is the best model.

As for LRBET modeling, we identified a single model which meets the specific regression model assumptions, namely APARCH-M(1,1) (Normal Distribution). Table 4 shows the final results.

Table no. 4

Results for estimation of heteroscedastic models

\begin{tabular}{|c|c|r|r|}
\hline Variables & \multicolumn{1}{|c|}{ CLRBET } & \multicolumn{1}{c|}{ SLRBET } & \multicolumn{1}{c|}{ LRBET } \\
\hline Parameters & $\begin{array}{c}\text { EGARCH(1,1)-M } \\
\text { (Student Distribution) }\end{array}$ & $\begin{array}{c}\text { EGARCH(1,1) -M } \\
\text { (Student Distribution). }\end{array}$ & $\begin{array}{c}\text { A-PARCH(1,1)-M } \\
\text { (Normal Distribution) }\end{array}$ \\
\hline$b_{0}$ & $0.058514(0.0014)$ & $-0.002694(0.9762)$ & $-0.028313(0.6481)$ \\
\hline$\hat{a}_{0}$ & & $-0.024587(0.8381)$ & $0.056411(0.4840)$ \\
\hline$\hat{a}_{1}$ & $0.052093(0.0179)$ & $0.194088(0.0000)$ & $0.119429(0.0000)$ \\
\hline$\hat{\alpha}_{0}$ & $-0.271268(0.0000)$ & $-0.247415(0.0000)$ & $0.159774(0.0000)$ \\
\hline$\hat{\alpha}_{1}$ & $0.511343(0.0000)$ & $0.423549(0.0000)$ & $0.146079(0.0000)$ \\
\hline$\hat{\gamma}_{1}$ & $-0.040132(0.1390)$ & $-0.090051(0.0213)$ & $0.059062(0.0016)$ \\
\hline$\hat{\beta}_{1}$ & $0.898021(0.0000)$ & $0.940185(0.0000)$ & $0.750085(0.0000)$ \\
\hline$\hat{\delta}_{1}$ & - & - & $3.106150(0.0000)$ \\
\hline
\end{tabular}

Remark: Results obtained by means of the Eviews software

The table above shows interesting yet predictable results on the return and risk of the BET index portfolio and implicitly of Bucharest Stock Exchange. If we analyze the results of the entire period considered, we may say that there is no connection between return and risk at Bucharest Stock Exchange. Therefore, investors with aversion for risk should take into account that if they 
undertake a higher risk by making investments on the BSE this does not necessarily mean a higher rate of return.

If we analyze the results separately, the situation is different between the economic growth and recession periods. The economic growth periods reveal a connection between return and volatility, whereas this is not the case in the economic recession periods. An investor with aversion for risk would be motivated to invest or speculate on the BSE during the economic growth periods, when he had higher return rates for bigger risks.

As for the volatility of the entire analyzed period, the estimated model shows us that it is asymmetric. Therefore, volatility is higher when most of the prices decrease, as compared to the general stock exchange price increase periods. Also, the analysis of the economic growth period reveals a different situation from the economic recession periods. Volatility rates are not asymmetric during the economic growth periods, yet, during the economic recession periods, they are asymmetric.

\section{Conclusions}

The latest studies on the relation between return and volatility dwell on the separate analysis of this connection during economic growth and recession, respectively. The results obtained support the existence of a series of significant differences. For this reason, the purpose of our paper was to discover whether these types of differences occur in Bucharest Stock Exchange, as well. In order to characterize Bucharest Stock Exchange, we considered the BET index portfolio, whose daily return rate was determined using the BET index prices.

Hence, we analyzed three rates of return, namely throughout the analyzed period, during the economic growth periods and during the economic recession periods. The analyzed return rates are leptokurtic, just as all the return rates of financial assets, which means that a BSE investor may either have very high profits, or incur considerable losses. Volatility clustering proves that return rates are dependent and may be modeled using heteroskedastic models. The descriptive return rate analysis between January 1 and April 27, 2011, as compared to the return rates in the economic growth and recession periods, reveals differences as concerns the expected rates of returns and volatilities. Also, they have a descending trend during economic recession periods.

Our research reveals no relation between return rate and volatility throughout the analyzed period. However, further to a separate analysis of the economic growth and recession, respectively, one may notice the existence of a connection between return rate and volatility, but only during the economic growth period. Also, volatility is asymmetric during economic recession periods, which triggers higher volatility when a general BSE price decrease occurs. The results obtained support our assumption according to which there is a direct positive relation between expected return and volatility during economic growth, which turns into a negative connection during economic recession. The results obtained have major implications for stock portfolio managers who are supposed to manage those portfolios in close connection with the business cycle stages

\section{Acknowledgement}

This work was cofinanced from the European Social Fund through Sectoral Operational Programme Human Resources Development 2007-2013, project number POSDRU/1.5/S/59184 „Performance and excellence in postdoctoral research in Romanian economics science domain”

\section{References}

1. Baillie R. T., DeGennarro R. P., 1990. Stock Return and Volatility, Journal of Fnancial and Quantitative Analysis, Vol. 25, No. 2, June, pp. 203-214. 
2. Berdot J.-P., 2003. Rentabilité et volatilités des indices boursiers. Une analyse comparative du BET, du Dow-Jones industrials set du CAC 40, Conférences, Iasi

3. Boollerslev T., 1986. Generalized Autoregressive Conditional Heterosckedasticity, Journal of Econometrics, 31, 307-327.

4. Bry G, Boschan C., 1971. Cyclical Analysis of Time Series: Selected Procedures and Computer Programs, NBER, New York

5. Ding Z., Granger C.W.J., Engle R.F., 1993. A long memory property of stock market returns and a new model. Journal of Empirical Finance 1, 83-10

6. Engle R.F., Lilien, D. M., Robbins, R.P., 1987. Estimating Time Varying Risk Premium in the Term Structure: The ARCH-M Model', Econometrica, 55, $391-407$.

7. Engle R. F., 1982. Autoregressive conditional heteroskedasticity with estimates of the variance of the United Kingdom inflation, Econometrica, 50, 987-1007.

8. Engle R.F., Bollerselv T.,1986. Modeling the persistence of conditional variances, Econometric Reviews, 5, 1-50.

9. Glosten L., Jagannathan R., Runkle D., 1993. On the relationship between the expected value and the volatility of the nominal excess return on stocks, Journal of Finance 46, 1779801.

10. Harding D., Pagan A., 2001. Extracting, Analysing and Using Cyclical Information, Mimeo, University of Melbourne.

11. Kim S.-W., Lee B.-S., 2008. Stock Returns, Asymmetric Volatility, Risc Aversion, and Business Cycle: Some New Evidence, Economic Inquiry, Vol. 46 (2), 131-148.

12. Koulakiotis A., Papasyriopoulos N., Molyneux P., 2006. More Evidence on the Relationship between Stock Price Returns and Volatility: A Note, International Research Journal of Finance and Economics, no. 1, 21-28.

13. Lintner J., 1965. The Valuation of Risk Assets and the Selection of Risky Investments in Stock Portfolios and Capital Budgets. Review of Economics and Statistics. 47:1, 13-37.

14. Mandelbrot B. B., 1963. The variation of certain speculative prices, Journal of Business, XXXVI (1963), 392-417.

15. Mills T. C., 1999. The Econometric Modeling of Financial Time Series, Cambridge University Press.

16. Mossin J., 1966. Equilibrium in a capital asset market. Econometrica 41, 768- 783.

17. Nelson D. B., 1991. Conditional heteroskedasticity in asset returns: A new approach, Econometrica. 59, 347-370.

18. Sharpe William F., 1964. Capital Asset Prices:A Theory of Market Equilibrium under Conditionsof Risk. Journal of Finance. 19:3, 425-42.

19. Theodossiou P., Lee U., 1995. Relationship between volatility and expected returns across international stock markets. Journal of Business Finance and Accounting 22, 289- 300.

20. EUROSTAT DATABASE http://epp.eurostat.ec.europa.eu/portal/page/portal/statistics/search_database 
APPENDIX 1 The results of testing stationarity for BET index portfolio return during economic growth, economic recession and throughout the analyzed period

\begin{tabular}{|c|c|c|c|}
\hline Characteristics & Model with intercept & $\begin{array}{l}\text { Model with intercept and } \\
\text { trend }\end{array}$ & $\begin{array}{l}\text { Model without intercept } \\
\text { and trend }\end{array}$ \\
\hline \multicolumn{4}{|l|}{ CLRBET } \\
\hline ADF test & -43.86864 & -43.86302 & -43.72802 \\
\hline Critical value(5\%) & -2.862644 & -3.411838 & -1.940967 \\
\hline Akaike & 3.869389 & 3.870201 & 3.871677 \\
\hline Schwarz & 3.874540 & 3.877928 & 3.874253 \\
\hline PP test & -43.86127 & -43.85534 & -43.77578 \\
\hline Critical value (5\%) & -2.862644 & -3.411838 & -1.940967 \\
\hline Akaike & 3.869389 & 3.870201 & 3.871677 \\
\hline Schwarz & 3.874540 & 3.877928 & 3.874253 \\
\hline KPSS test & 0.069179 & 0.045194 & - \\
\hline Critical value(5\%) & 0.463000 & 0.146000 & - \\
\hline Akaike & 3.872866 & 3.873665 & - \\
\hline Schwarz & 3.875440 & 3.878815 & - \\
\hline \multicolumn{4}{|l|}{ SLRBET } \\
\hline ADF test & -22.63208 & -22.98102 & -22.63912 \\
\hline Critical value(5\%) & -2.865235 & -3.415909 & -1.941252 \\
\hline Akaike & 4.276716 & 4.266194 & 4.274310 \\
\hline Schwarz & 4.289179 & 4.284890 & 4.280542 \\
\hline PP test & -22.58433 & -22.83556 & -22.59324 \\
\hline Critical value(5\%) & -2.865235 & -3.415909 & -1.941252 \\
\hline Akaike & 4.276716 & 4.266194 & 4.274310 \\
\hline Schwarz & 4.289179 & 4.284890 & 4.280542 \\
\hline KPSS test & 1.265155 & 0.197490 & - \\
\hline Critical value(5\%) & 0.463000 & 0.146000 & - \\
\hline Akaike & 4.305605 & 4.289542 & - \\
\hline Schwarz & 4.311830 & 4.301992 & - \\
\hline \multicolumn{4}{|l|}{ LRBET } \\
\hline ADF test & -48.67901 & -48.73292 & -48.58288 \\
\hline Critical value(5\%) & -2.862319 & -3.411327 & -1.940931 \\
\hline Akaike & 3.987991 & 3.987531 & 3.989223 \\
\hline Schwarz & 3.992046 & 3.993613 & 3.991250 \\
\hline PP test & -48.82944 & -48.82727 & -48.84224 \\
\hline Critical value(5\%) & -2.862319 & -3.411327 & -1.940931 \\
\hline Akaike & 3.987991 & 3.987531 & 3.989223 \\
\hline Schwarz & 3.992046 & 3.993613 & 3.991250 \\
\hline KPSS test & 0.512515 & 0.120931 & - \\
\hline Critical value(5\%) & 0.739000 & 0.216000 & - \\
\hline Akaike & 3.999385 & 3.998650 & - \\
\hline Schwarz & 4.001412 & 4.002705 & - \\
\hline
\end{tabular}


APPENDIX 2 Total and partial autocorrelation functions of stationary BET index portfolio returns throughout the analyzed period, during economic growth and economic recession

Table no 1.

Values of partial and total autocorrelation functions and Ljung Box test for LRBET and CLRBET

\begin{tabular}{|r|r|r|r|r|r|r|r|r|}
\hline & \multicolumn{9}{|c|}{ LRBET } & \multicolumn{4}{c|}{ CLRBET } \\
\hline & \multicolumn{1}{|c|}{ AC } & \multicolumn{1}{|c|}{ PAC } & \multicolumn{1}{c|}{ Q-Stat } & \multicolumn{1}{c|}{ Prob } & \multicolumn{1}{c|}{ AC } & \multicolumn{1}{c|}{ PAC } & \multicolumn{1}{c|}{ Q-Stat } & Prob \\
\hline 1 & 0.108 & 0.108 & 34.681 & 0.000 & 0.069 & 0.069 & 10.687 & 0.001 \\
\hline 2 & 0.011 & -0.000 & 35.071 & 0.000 & 0.001 & -0.004 & 10.689 & 0.005 \\
\hline 3 & -0.032 & -0.033 & 38.038 & 0.000 & -0.038 & -0.038 & 13.941 & 0.003 \\
\hline 4 & 0.001 & 0.008 & 38.042 & 0.000 & 0.019 & 0.025 & 14.779 & 0.005 \\
\hline 5 & 0.026 & 0.025 & 39.992 & 0.000 & 0.031 & 0.028 & 16.931 & 0.005 \\
\hline 6 & 0.014 & 0.007 & 40.546 & 0.000 & 0.031 & 0.026 & 19.102 & 0.004 \\
\hline 7 & 0.009 & 0.006 & 40.764 & 0.000 & -0.016 & -0.018 & 19.671 & 0.006 \\
\hline 8 & 0.030 & 0.030 & 43.352 & 0.000 & 0.025 & 0.029 & 21.050 & 0.007 \\
\hline 9 & 0.003 & -0.003 & 43.373 & 0.000 & 0.007 & 0.004 & 21.164 & 0.012 \\
\hline 10 & 0.011 & 0.010 & 43.728 & 0.000 & 0.029 & 0.025 & 23.051 & 0.011 \\
\hline 11 & 0.019 & 0.019 & 44.838 & 0.000 & -0.001 & -0.004 & 23.053 & 0.017 \\
\hline 12 & 0.013 & 0.008 & 45.318 & 0.000 & 0.016 & 0.016 & 23.599 & 0.023 \\
\hline
\end{tabular}

Table no 2.

Values of partial and total autocorrelation functions and Ljung Box test for SLRBET

\begin{tabular}{r|r|r|r|r|}
\hline & \multicolumn{4}{|c|}{ SLRBE } \\
\hline & \multicolumn{1}{|c|}{ AC } & \multicolumn{1}{c|}{ PAC } & \multicolumn{1}{c|}{ Q-Stat } & Prob \\
\hline 1 & 0.164 & 0.164 & 20.082 & 0.000 \\
\hline 2 & 0.028 & 0.001 & 20.646 & 0.000 \\
\hline 3 & -0.037 & -0.043 & 21.658 & 0.000 \\
\hline 4 & -0.045 & -0.033 & 23.144 & 0.000 \\
\hline 5 & -0.006 & 0.008 & 23.170 & 0.000 \\
\hline 6 & -0.031 & -0.032 & 23.868 & 0.001 \\
\hline 7 & 0.056 & 0.065 & 26.194 & 0.000 \\
\hline 8 & 0.029 & 0.010 & 26.846 & 0.001 \\
\hline 9 & -0.039 & -0.052 & 27.978 & 0.001 \\
\hline 10 & -0.033 & -0.018 & 28.799 & 0.001 \\
\hline 11 & 0.042 & 0.061 & 30.128 & 0.002 \\
\hline 12 & 0.003 & -0.017 & 30.134 & 0.003 \\
\hline
\end{tabular}

\section{APPENDIX 3. Estimation of heteroscedastic models for CLRBET}

Table no.1

Schwarz criterion values for various $\operatorname{ARMA}(p, q)$ models for CLRBET

\begin{tabular}{|c|c|c|c|c|c|}
\hline AR/MA & 0 & 1 & 2 & 3 & 4 \\
\hline 0 & 3.872405 & 3.872009 & 3.875491 & 3.877379 & 3.880627 \\
\hline 1 & $\mathbf{3 . 8 6 1 4 1 1}$ & 3.864646 & 3.867907 & 3.870220 & 3.872916 \\
\hline 2 & 3.864502 & 3.864413 & 3.867776 & 3.871249 & 3.874166 \\
\hline 3 & 3.866371 & 3.867998 & 3.871247 & 3.871214 & 3.874686 \\
\hline 4 & 3.869634 & 3.871043 & 3.874355 & 3.875151 & 3.876969 \\
\hline
\end{tabular}


Table no. 2.

Information criteria values of the estimated heteroscedastic models for CLRBET

\begin{tabular}{|l|c|c|c|c|c|c|}
\hline & \multicolumn{3}{|c|}{ EGARCH(1,1)-M } & \multicolumn{3}{c|}{ EGARCH(1,2)-M } \\
\hline $\begin{array}{c}\text { Information } \\
\text { criteria }\end{array}$ & $\begin{array}{c}\text { Normal } \\
\text { Distribution }\end{array}$ & $\begin{array}{c}\text { Student } \\
\text { Distribution }\end{array}$ & GED & $\begin{array}{c}\text { Normal } \\
\text { Distribution }\end{array}$ & $\begin{array}{c}\text { Student } \\
\text { Distribution }\end{array}$ & GED \\
\hline Akaike & 3,567646 & 3,459793 & 3,457762 & 3,557770 & 3,457434 & 3,454792 \\
\hline Schwarz & 3,585676 & 3,480398 & 3,478367 & 3,578376 & 3,480615 & 3,477973 \\
\hline Hannan-Quinn & 3,574233 & 3,467320 & 3,465289 & 3,565297 & 3,465902 & 3,463260 \\
\hline Adjusted R ${ }^{2}$ & 0,001396 & 0,003797 & 0,001795 & 0.000846 & 0.003701 & 0.001651 \\
\hline Regres.hypot. & not met & were met. & not met & not met & not met & not met \\
\hline
\end{tabular}

Table no. 2 (continuation)

Information criteria values of the estimated heteroscedastic models for CLRBET

\begin{tabular}{|l|r|c|c|r|r|r|}
\hline & \multicolumn{3}{|c|}{ APARCH(1,1)-M } & \multicolumn{3}{c|}{ GJR(1,1)-M } \\
\hline $\begin{array}{c}\text { Information } \\
\text { criteria }\end{array}$ & $\begin{array}{c}\text { Normal } \\
\text { Distribution }\end{array}$ & $\begin{array}{c}\text { Student } \\
\text { Distribution }\end{array}$ & GED & $\begin{array}{c}\text { Normal } \\
\text { Distribution }\end{array}$ & $\begin{array}{c}\text { Student } \\
\text { Distribution }\end{array}$ & GED \\
\hline Akaike & 3,543218 & & 3,450415 & 3,546374 & 3,458199 & 3,449559 \\
\hline Schwarz & 3,563824 & & 3,473596 & 3,564403 & 3,478804 & 3,470165 \\
\hline Hannan-Quinn & 3,550745 & & 3,458883 & 3,552960 & 3,465726 & 3,457086 \\
\hline Adjusted ${ }^{2}$ & 0,003690 & & 0,001595 & 0,003703 & 0,003272 & 0,001623 \\
\hline Regres.hypot. & were met. & & not met & not met & not met & not met \\
\hline
\end{tabular}

\section{APPENDIX 4 Estimation of heteroscedastic models for SLRBET}

Table no. 1.

Schwarz criterion values for various ARMA(p,q) models for SLR
\begin{tabular}{|c|c|c|c|c|c|}
\hline AR/ MA & 0.000000 & 1.000000 & 2.000000 & 3.000000 & 4.000000 \\
\hline 0.000000 & 4.296668 & 4.278895 & 4.286411 & 4.294832 & 4.302248 \\
\hline 1.000000 & $\mathbf{4 . 2 7 8 1 6 7}$ & 4.287118 & 4.294970 & 4.303160 & 4.307884 \\
\hline 2.000000 & 4.287136 & 4.295457 & 4.303294 & 4.292695 & 4.316845 \\
\hline 3.000000 & 4.294303 & 4.302706 & 4.305703 & 4.316541 & 4.323024 \\
\hline 4.000000 & 4.302199 & 4.307582 & 4.316550 & 4.322161 & 4.330824 \\
\hline
\end{tabular}

Table no. 2

Information criteria values of the estimated heteroscedastic models for SLRBET

\begin{tabular}{|l|r|r|r|r|r|r|}
\hline & \multicolumn{3}{|c|}{ GARCH(1,1)-M } & \multicolumn{2}{c|}{ EGARCH(1,1) -M } \\
\hline $\begin{array}{c}\text { Information } \\
\text { criteria }\end{array}$ & $\begin{array}{c}\text { Normal } \\
\text { Distribution }\end{array}$ & $\begin{array}{c}\text { Student } \\
\text { Distribution }\end{array}$ & GED & $\begin{array}{c}\text { Normal } \\
\text { Distribution }\end{array}$ & $\begin{array}{c}\text { Student } \\
\text { Distribution }\end{array}$ & GED \\
\hline Akaike & 3,866529 & 3,757918 & 3,770038 & 3,864221 & 3,752276 & 3,768306 \\
\hline Schwarz & 3,903920 & 3,803541 & 3,813661 & 3,907844 & 3,802131 & 3,818160 \\
\hline Hannan-Quinn & 3,880947 & 3,774739 & 3,786858 & 3,881041 & 3,771499 & 3,787529 \\
\hline Adjusted R & 0,021850 & 0,024941 & 0,025407 & 0,010279 & 0,023235 & 0,024620 \\
\hline Regres.hypot. & were met & were met & were met & were met & were met & were met \\
\hline
\end{tabular}

Table no. 2 (continuation)

Information criteria values of the estimated heteroscedastic models for SLRBET

\begin{tabular}{|l|r|r|r|r|r|r|}
\hline & \multicolumn{3}{|c|}{ APARCH(1,1)-M } & \multicolumn{1}{c|}{ GJR(1,1)-M } \\
\hline Information criteria & $\begin{array}{c}\text { Normal } \\
\text { Distribution }\end{array}$ & $\begin{array}{c}\text { Student } \\
\text { Distribution }\end{array}$ & GED & $\begin{array}{c}\text { Normal } \\
\text { Distribution }\end{array}$ & $\begin{array}{c}\text { Student } \\
\text { Distribution }\end{array}$ & GED \\
\hline Akaike & 3,851580 & 3,754194 & 3,764614 & 3,850029 & 3,752906 & 3,762089 \\
\hline Schwarz & 3,901435 & 3,810280 & 3,820700 & 3,893652 & 3,802760 & 3,811943 \\
\hline Hannan-Quinn & 3,870804 & 3,775820 & 3,786240 & 3,866850 & 3,772129 & 3,781312 \\
\hline Adjusted R ${ }^{2}$ & 0,022951 & 0,024043 & 0,024897 & 0,023006 & 0,024374 & 0,025056 \\
\hline Regres.hypot. & were met & were met & were met & not met & not met & not met \\
\hline
\end{tabular}




\section{ANEXA 5 Estimation of heteroscedastic models for LRBET}

Table no. 1.

Schwarz criterion values for various ARMA(p,q) models for LRB
\begin{tabular}{|c|c|c|c|c|c|}
\hline AR / MA & 0 & 1 & 2 & 3 & 4 \\
\hline 0 & 3.994778 & 3.986817 & 3.988157 & 3.989798 & 3.992465 \\
\hline 1 & 3.983937 & 3.986626 & 3.990723 & 3.992816 & 3.995347 \\
\hline 2 & 3.988961 & 3.991225 & 3.992067 & 3.990461 & 3.991486 \\
\hline 3 & 3.990186 & 3.988894 & 3.989725 & 3.989518 & 3.991425 \\
\hline 4 & 3.991002 & 3.988919 & 3.989979 & 3.991113 & 3.992272 \\
\hline
\end{tabular}

Table no. 2.

Information criteria values of the estimated heteroscedastic models for LRBET

\begin{tabular}{|l|r|r|r|r|r|r|}
\hline & \multicolumn{3}{|c|}{ GARCH(1,1)-M } & \multicolumn{3}{c|}{ GARCH(1,2)-M } \\
\hline \multicolumn{1}{|c|}{$\begin{array}{c}\text { Information } \\
\text { criteria }\end{array}$} & $\begin{array}{c}\text { Normal } \\
\text { Distribution }\end{array}$ & $\begin{array}{c}\text { Student } \\
\text { Distribution }\end{array}$ & GED & $\begin{array}{c}\text { Normal } \\
\text { Distribution }\end{array}$ & $\begin{array}{c}\text { Student } \\
\text { Distribution }\end{array}$ & GED \\
\hline Akaike & 3.631691 & 3.531238 & 3.528495 & 3.627378 & 3.528931 & 3.526268 \\
\hline Schwarz & 3.643860 & 3.545434 & 3.542692 & 3.641574 & 3.545156 & 3.542493 \\
\hline Hannan-Quinn & 3.636072 & 3.536348 & 3.533606 & 3.632488 & 3.534772 & 3.532109 \\
\hline Adjusted R ${ }^{2}$ & 0.010565 & 0.010455 & 0.009390 & 0.010538 & 0.010490 & 0.009503 \\
\hline Regres.hypot. & not met & not met & not met & not met & not met & not met \\
\hline
\end{tabular}

Table no. 2 (continuation)

Information criteria values of the estimated heteroscedastic models for LRBET

\begin{tabular}{|l|r|r|r|r|r|r|}
\hline & \multicolumn{3}{|c|}{ EGARCH(1,1)-M } & \multicolumn{3}{c|}{ EGARCH(1,2)-M } \\
\hline $\begin{array}{c}\text { Information } \\
\text { criteria }\end{array}$ & $\begin{array}{c}\text { Normal } \\
\text { Distribution }\end{array}$ & $\begin{array}{c}\text { Student } \\
\text { Distribution }\end{array}$ & GED & $\begin{array}{c}\text { Normal } \\
\text { Distribution }\end{array}$ & $\begin{array}{c}\text { Student } \\
\text { Distribution }\end{array}$ & GED \\
\hline Akaike & 3.654074 & 3.532093 & 3.536084 & 3.649354 & 3.529886 & 3.533805 \\
\hline Schwarz & 3.668271 & 3.548318 & 3.552309 & 3.665578 & 3.548139 & 3.552058 \\
\hline Hannan-Quinn & 3.659185 & 3.537934 & 3.541925 & 3.655194 & 3.536457 & 3.540376 \\
\hline Adjusted R & 0.006264 & 0.010778 & 0.009906 & 0.005959 & 0.010735 & 0.009731 \\
\hline Regres.hypot. & not met & not met & not met & not met & not met & not met \\
\hline
\end{tabular}

Table no. 2 (continuation)

Information criteria values of the estimated heteroscedastic models for LRBET

\begin{tabular}{|c|c|c|c|c|c|c|}
\hline & \multicolumn{3}{|c|}{ APARCH(1,1)-M } & \multicolumn{3}{|c|}{ GJR(1,1)-M } \\
\hline Information criteria & $\begin{array}{c}\text { Normal } \\
\text { Distribution }\end{array}$ & $\begin{array}{c}\text { Student } \\
\text { Distribution }\end{array}$ & GED & $\begin{array}{c}\text { Normal } \\
\text { Distribution }\end{array}$ & $\begin{array}{c}\text { Student } \\
\text { Distribution }\end{array}$ & GED \\
\hline Akaike & 3.626184 & 3.530726 & 3.527898 & 3.630909 & 3.530523 & 3.527258 \\
\hline Schwarz & 3.642408 & 3.548979 & 3.546151 & 3.645105 & 3.546748 & 3.543483 \\
\hline Hannan-Quinn & 3.632024 & 3.537297 & 3.534469 & 3.636019 & 3.536364 & 3.533099 \\
\hline Adjusted $\mathrm{R}^{2}$ & 0.010737 & 0.010693 & 0.009918 & 0.010838 & 0.010781 & 0.009874 \\
\hline Regres.hypot. & were met & not met & not met & not met & not met & not met \\
\hline
\end{tabular}

